\title{
Influence of electric fishing lights on sink rates of baited hooks in Brazilian pelagic longline fisheries: implications for seabird bycatch
}

\author{
Dimas Gianuca ${ }^{1,2 *}$, Rodrigo Sant'Ana ${ }^{2,3}$, Tatiana Neves ${ }^{2}$ \\ ${ }^{1}$ Environment and Sustainability Institute - University of Exeter (Penryn Campus, Penryn, Cornwall, UK, TR10 9FE) \\ ${ }^{2}$ Projeto Albatroz (Marechal Hermes 35, Santos, SP, Brazil, 11025-040) \\ ${ }^{3}$ Universidade do Vale do Itajaí (Uruguai 458, Itajaí, SC, Brazil, 88302-202) \\ *Corresponding author: dgianuca@gmail.com
}

The incidental mortality of seabirds in longline fisheries is the major cause of the population declines threatening most albatross and large petrel species (LEWISON; CROWDER, 2003; ANDERSON et al., 2011). Currently there is a large and growing number of solutions for reducing seabird mortality on longlines. The combination of certain mitigation measures can greatly reduce seabird bycatch, although no single mitigation measure can reliably prevent seabird mortality. The combination of night setting, bird scaring lines and well-weighted branch lines are the best practice for the mitigation of seabird bycatch in pelagic longline fisheries (ACAP, 2014).

The sink rate of baited hooks is arguably the major issue to be addressed to reduce seabird-longline interactions. Even when scaring lines are used, to make them effective the baited hooks must attain safe depths (i.e. deeper than the diving range of most petrel species) within the area protected by a scaring line. Many factors are known to affect the sink rate of baited hooks on pelagic longlines, such as the bait type (e.g. squid, mackerel, sardine, skipjack flash) and its state (e.g. dead or alive, frozen or thawed); the mainline tension during deployment; and line weight regimes (the use or not of leaded swivels, as well as their mass and distance from the hooks) (ANDERSON; MCARDLE, 2002; PETERSON et al., 2008, ROBERTSON et al., 2010; ROBERTSON et al., 2013).

The best weighting regimes recommended are those that reach a depth of $10 \mathrm{~m}$ while under the protection of a scaring line with $\sim 100 \mathrm{~m}$ aerial coverage (PETERSEN et al., 2008, MELVIN et al., 2009a). Experiments have indicated that $\geq 60 \mathrm{~g}$ placed no more than $3 \mathrm{~m}$ from the

http://dx.doi.org/10.1590/S1679-87592016092306401 hooks is likely to achieve satisfactory sink rates under most operational conditions (MELVIN et al., 2009b; ROBERTSON et al., 2010; GIANUCA et al., 2011). Accordingly, among the best practices to reduce seabird mortality in pelagic longline fisheries recommended by the Agreement on the Conservation of Albatrosses and Petrels (ACAP, 2014) and the International Commission for the Conservation of Atlantic Tunas (ICCAT, 2011), is to use specific line-weighting regimes that ensure appropriate sink rates. The three recommended configurations are: weight greater than $45 \mathrm{~g}$ attached within $1 \mathrm{~m}$ of the hook or greater than $60 \mathrm{~g}$ attached within $3.5 \mathrm{~m}$ of the hook or greater than $98 \mathrm{~g}$ attached within $4 \mathrm{~m}$ of the hook. Positioning the weight farther than $4 \mathrm{~m}$ from the hook is not recommended.

The use of chemical light sticks and more recently battery powered electric fishing lights (EFL), increases catch rates by attracting target species directly or by attracting their prey (BERKELEY et al., 1981; FREEMAN, 1989; ORTIZ; SCOTT, 2001; HAZIN et al., 2005). Despite the addition of this kind of device (usually $\sim 2 \mathrm{~m}$ from the hooks) alters the surface/volume ratio of the terminal portion of the branch lines and potentially the sink rate of baited hooks, no investigation has yet been undertaken on this issue.

EFL have recently been adopted by the southern Brazilian pelagic longline fleet, and their use and popularity are growing among fishermen and ship owners. Each EFL carries two AA batteries and, given its weight out of the water $(\sim 160 \mathrm{~g})$, some fishermen argue that the use of this kind of device increases the sink rate of baited hooks, and using this untested premise as justification for not adopting the required line-weighting regimes.

In the light of this scenario, the aim of the present 
study was to investigate the effect of EFL on the sink rate of baited hooks on branch lines with $3.5 \mathrm{~m}$ leaders (recommended line-weighting) and $5.5 \mathrm{~m}$ leaders (preferred by southern Brazilian longliners).

The southern Brazilian Fleet is composed of around 50 steel or wooden hulled vessels, of 15 to $29 \mathrm{~m}$ total length. This fleet targets tunas, swordfish and sharks, and operates off south and southeast Brazil, from $25^{\circ} \mathrm{S}$ to $35^{\circ} \mathrm{S}$, and $45^{\circ}$ to $55^{\circ} \mathrm{W}$, using mainly the ports of Rio Grande-RS

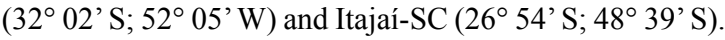

The fishing gear used by the southern Brazilian pelagic longline vessels is composed, in general, by a continuous mainline made of $3.0 \mathrm{~mm}$ or $3.8 \mathrm{~mm}$ nylon monofilament, ranging between 20 and 40 miles long. Radio buoys are attached at intervals of 45 small buoys, the number of radio buoys varies between three and seven, and are attached to the mainline by a propylene multifilament 15.0 $\mathrm{mm}$ cable $20 \mathrm{~m}$ long. The section of mainline between two small buoys is called basket, to which are attached from five to seven branch lines containing one hook at the end. The branch lines are made of $2.0 \mathrm{~mm}$ nylon monofilament, ranging between 10 and $50 \mathrm{~m}$ long, bearing one lead swivel (60 or $75 \mathrm{~g}$ ) in addition to the hook. The length of the leader (portion of line between the hook and the leaded swivel) varies from $3 \mathrm{~m}$ to $10 \mathrm{~m}$, though $\sim 5.5 \mathrm{~m}$ (3 fathoms) is the most popular configuration in the southern Brazilian fleet. In general the total number of hooks on the longline varies from 600 to 1,200 . The variations in style and magnitude of the fishing gear presented above are related to the preferences of each skipper and to the infrastructure of each vessel.

Recently, electric fishing lights have been substituting chemical light sticks in the southern Brazilian fleet, especially by fishermen targeting swordfish. Among the longliners using electric fishing lights, the proportion of the total branch lines containing this device ranges from $25 \%$ to $80 \%$, according to the preference of each skipper. The electric fishing light most used by southern Brazilian longliners, the model used in the present study, is made of poly carbonate resin, contains $2 \mathrm{AA}$ batteries, and is attached to a branch line with small snaps, immediately above the leaded swivels (Figure 1). This device has a $15 \mathrm{~cm}$ circumference at its widest point, is $9 \mathrm{~cm}$ in length, and has external and internal volumes, respectively, of 120 $\mathrm{ml}$ and $40 \mathrm{ml}$. When loaded with AA batteries $(10 \mathrm{ml}$ each) the electric lights contain $20 \mathrm{ml}$ of air, and weight $160 \mathrm{~g}$ each, including the snap.

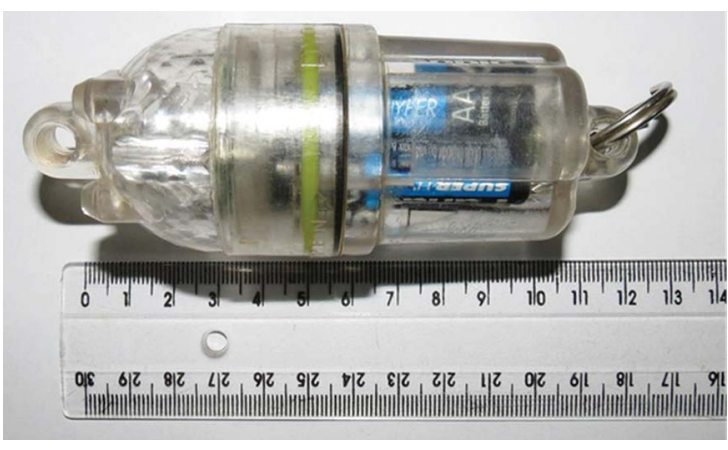

Figure 1. Model of electric fishing light commonly used by southern Brazilian pelagic longline fleet.

The authors conducted two fishing trips on board two pelagic longliners of the southern Brazilian fleet to collect data on the effect of the electric lights on the sink rates of baited hooks. The first trip was undertaken in August 2012 on board the FV Ana Amaral I, a wooden vessel $29.5 \mathrm{~m}$ length, using branch lines with $75 \mathrm{~g}$ leaded swivels positioned at $4 \mathrm{~m}$ from the $10 / 0 \mathrm{~J}$ hooks. The second trip was made in October 2012 on board the FV Rei do Atum, a $22 \mathrm{~m}$ iron-hulled vessel, using 60-75 g leaded swivels positioned at $5.5 \mathrm{~m}$ from the $9 / 0$ circle hooks. On both vessels the branch lines were $\sim 40 \mathrm{~m}$ long with a $30 \mathrm{~cm}$ wire trace, and the setting speed was around 6 knots.

On each vessel we provided specifically built experimental branch lines that were deployed amongst the normal gear of the vessels. We established four treatments to investigate sink rates: (Treatment 1) $3.5 \mathrm{~m}$ leader, (Treatment 2) $3.5 \mathrm{~m}$ leader plus EFL, (Treatment 3) $5.5 \mathrm{~m}$ leader, and (Treatment 4) $5.5 \mathrm{~m}$ leader plus EFL. All the experimental branch lines contained $75 \mathrm{~g}$ leaded swivels, and thawed skipjack flesh of similar size as bait $(\sim 20 \mathrm{~cm}$ length). During the setting operations, the experimental branch lines of each treatment were fitted with CEFAS G5 Time Depth Recorders (TDRs), $30 \mathrm{~cm}$ from the hooks. These were handed to fishermen and attached to the main line in the middle of the basket. TDRs were set to record time and depth (pressure) at one-second intervals. Water entry time was recorded using a wrist watch that was previously synchronized with the TDRs before each set.

For each TDR treatment we verified the time to $2 \mathrm{~m}, 4$ $\mathrm{m}, 6 \mathrm{~m}$ and $10 \mathrm{~m}$ depth, and then calculated the sink rates of baited hooks within each of the following depth strata: 0-2 m, 2-4 m, 4-6 m and 6-10 m. In addition we verified the depth after $17 \mathrm{sec}$ and $27 \mathrm{sec}$, which corresponds, respectively, to $50 \mathrm{~m}$ and $80 \mathrm{~m}$ astern, assuming a setting velocity of 6 knots $(2.96 \mathrm{~m} / \mathrm{s})$. These distances were selected because $50 \mathrm{~m}$ astern is the critical area for seabird 
interactions in the absence of a scaring line (MELVIN; WALKER, 2009; GIANUCA et al., 2011; JIMÉNEZ et al., 2012) and $80 \mathrm{~m}$ is the mean aerial coverage of the Brazilian short streamers scaring line (GIANUCA et al., 2011).

Mean sink rates for each 0-2 m, 2-4 m, 4-6 m and 6-10 $\mathrm{m}$ strata, as well as mean depth of baited hooks after 17 and $27 \mathrm{sec}$, were compared between treatments using One Way ANOVA. The mean times to sink to $2 \mathrm{~m}, 4 \mathrm{~m}, 6 \mathrm{~m}$ and $10 \mathrm{~m}$ were compared between treatments using One Way ANOVA after square root transformation. A Tuckey test was conducted a posteriori for both analyses.

Over 11 sets we obtained 66 sink profiles of baited hooks; 16 with a $3.5 \mathrm{~m}$ leader, 17 with a $3.5 \mathrm{~m}$ leader plus EFL, 15 with a $5.5 \mathrm{~m}$ leader, and 15 with a $5.5 \mathrm{~m}$ leader plus EFL. Four sink profiles were excluded from statistical analyses as they presented unusual patterns (one for $3.5 \mathrm{~m}$ and three for $3.5 \mathrm{~m}$ leader plus EFL).

Baited hooks with 3.5 leaders with and without EFL sank at similar rates (Table 1, Figure 2), reaching $2 \mathrm{~m}, 4$ $\mathrm{m}$ and $6 \mathrm{~m}$ depths without significant differences (Figure 3), and were at similar depth after 17 and $27 \mathrm{sec}$ (Figure 4). Baited hooks with $5.5 \mathrm{~m}$ leaders without EFL sank significantly slower than both of those with 3.5 leaders with and without EFL. The addition of EFL to $5.5 \mathrm{~m}$ leaders slightly increased sink rates, which resulted in a sink performance intermediate between $3.5 \mathrm{~m}$ (with and without EFL) and $5.5 \mathrm{~m}$ leaders without EFL (Figures 2, 3 and 4).

The mean depth of baited hooks with $3.5 \mathrm{~m}$ leaders, with and without EFL, 27 seconds after setting was deeper than $10 \mathrm{~m}$ (10.6 $\mathrm{m}$ and $11.2 \mathrm{~m}$, respectively). In contrast, with $5.5 \mathrm{~m}$ leaders, with and without EFL, the mean depth of baited hooks did not reach the $10 \mathrm{~m}$ depth benchmark within the same time period $(9.3 \mathrm{~m}$ and 7.6 $\mathrm{m}$, respectively), yet the performance of the $5.5 \mathrm{~m}$ leader was improved with the addition of EFL (Figure 4). After 27 seconds, the mean depth of baited hooks with $5.5 \mathrm{~m}$ leaders without EFL was significantly shallower than that of those on $3.5 \mathrm{~m}$ leaders with and without EFL $(\mathrm{F}=5.346$; $p<0.01-p<0.05$ ), while leaders with $5.5 \mathrm{~m}$ leaders with EFL showed mean values intermediate between $3.5 \mathrm{~m}$ (with and without EFL) and $5.5 \mathrm{~m}$ leaders without EFL (Figure 4).

One baited hook with a $3.5 \mathrm{~m}$ leader plus EFL was abruptly raised from $7.0 \mathrm{~m}$ (22 sec after deployment) to $1.2 \mathrm{~m}$ depth, and another one with $3.5 \mathrm{~m}$ leader and no EFL was raised from $9.5 \mathrm{~m}$ (37 sec after deployment) to $0.5 \mathrm{~m}$ depth. These two events were interpreted as interactions with medium-sized diving petrels.

This study presents for the first time the sink rates of baited hooks of the Brazilian pelagic longline fisheries in accordance with one of the ACAP and ICCAT bestpractice line weighting recommendations (ICCAT, 2011; ACAP, 2014), in addition to testing the effect of EFL on the sink rates. Our results indicate that $3.5 \mathrm{~m}$ leaders with $75 \mathrm{~g}$ leaded swivels are likely to achieve satisfactory sink rates under Brazilian pelagic longline fishing conditions, while the $5.5 \mathrm{~m}$ leaders did not, thus supporting international recommendations (ICCAT, 2001; ACAP, 2014) and agreeing with other studies demonstrating that shorter leaders increase sink rates (ROBERTSON et al., 2010; GIANUCA et al., 2011; ROBERTSON et al., 2013).

The use of electric fishing lights did not influence significantly the sink rate of baited hooks with $3.5 \mathrm{~m}$ leaders, which is one of the line weighting regimes recommended by ICCAT (2011) and ACAP (2014), although it did increased sink rates slightly when longer leaders were used $(5.5 \mathrm{~m})$. Despite the presence of EFL enhanced sink rates in $5.5 \mathrm{~m}$ leaders, this improvement was not enough to equal the performance of $3.5 \mathrm{~m}$ leaders. Baited hooks of both $5.5 \mathrm{~m}$ leaders with and without EFL did not, on average, reach the $10 \mathrm{~m}$ depth "low risk" benchmark within $80 \mathrm{~m}$ astern, thus continuing to be relatively available for medium size diving petrels beyond the potential coverage of a scaring line (HUIN, 1994; RONCONI et al., 2010; ROLLINSON et al., 2014). However, it should be mentioned that $10 \mathrm{~m}$ depth is an arbitrary benchmark necessary for the establishment of sink rate goals in mitigation measurement research (PETERSEN et al., 2008; MELVIN et al., 2009b; ROBERTSON et al., 2010), even when medium-sized petrels can dive deeper than that (HUIN, 1994; RONCONI et al., 2010; ROLLINSON et al., 2014). Said that, the average depth of $9.3 \mathrm{~m}$ after 27 sec. represents a reasonable sink performance, which is not too far short of the $10 \mathrm{~m}$ depth benchmark.

Taking into account longline settings without a scaring line, the critical area for seabird interactions is within 50 astern (MELVIN; WALKER, 2009; GIANUCA et al., 2011; JIMÉNEZ et al., 2012). Thus, when 5.5 m leaders were used, whether combined with EFL or not, the mean depth of baited hooks in this critical zone was also within the dive range not only of medium-sized diving petrels, but also of Thalassarche albatrosses, able to reach $5 \mathrm{~m}$ depth (PRINCE et al., 1994). By contrast, the mean depth of baited hooks with $3.5 \mathrm{~m}$ leaders, regardless of the addition 
Table 1. Mean sink rates $(\mathrm{m} / \mathrm{sec})$ of baited hooks for each depth stratum according to leader length $(3.5 \mathrm{~m}$ and $5.5 \mathrm{~m})$ and presence or absence of electric fishing lights (EFL). Also presented are One-way ANOVA results comparing the effect of EFL on sink rate of baited hooks with 3.5 and $5.5 \mathrm{~m}$ leaders, as well as the effect of $5.5 \mathrm{~m}$ leaders on sink rate of baited hooks in comparison with $3.5 \mathrm{~m}$ leaders.

\begin{tabular}{|c|c|c|c|c|c|}
\hline Depth strata & 3.5 & $3.5+\mathrm{EFL}$ & Difference & $\mathrm{F}$ & $\mathrm{p}$ \\
\hline $0-2$ & 0.281 & 0.248 & -0.033 & 1.291 & 0.265 \\
\hline $2-4$ & 0.487 & 0.473 & -0.014 & 0.100 & 0.753 \\
\hline $4-6$ & 0.515 & 0.466 & -0.049 & 0.672 & 0.575 \\
\hline $6-10$ & 0.480 & 0.486 & 0.006 & 0.020 & 0.884 \\
\hline Depth strata & 5.5 & $5.5+\mathrm{EFL}$ & Difference & $\mathrm{F}$ & $\mathrm{p}$ \\
\hline $0-2$ & 0.182 & 0.245 & 0.063 & 5.671 & $0.023^{*}$ \\
\hline $2-4$ & 0.377 & 0.436 & 0.059 & 2.476 & 0.124 \\
\hline $4-6$ & 0.431 & 0.426 & -0.005 & 0.014 & 0.904 \\
\hline $6-10$ & 0.376 & 0.408 & 0.033 & 0.493 & 0.505 \\
\hline Depth strata & 3.5 & 5.5 & Difference & $\mathrm{F}$ & $\mathrm{p}$ \\
\hline $0-2$ & 0.281 & 0.182 & -0.100 & 16.552 & $0.001 * *$ \\
\hline $2-4$ & 0.487 & 0.377 & -0.110 & 10.221 & $0.004 * *$ \\
\hline $4-6$ & 0.515 & 0.431 & -0.084 & 2.938 & 0.094 \\
\hline $6-10$ & 0.480 & 0.376 & -0.104 & 8.143 & $0.009 * *$ \\
\hline Depth strata & $3.5+\mathrm{EFL}$ & $5.5+\mathrm{EFL}$ & Difference & $\mathrm{F}$ & $\mathrm{p}$ \\
\hline $0-2$ & 0.248 & 0.245 & -0.004 & 0.015 & 0.899 \\
\hline $2-4$ & 0.473 & 0.436 & -0.037 & 0.589 & 0.544 \\
\hline $4-6$ & 0.466 & 0.426 & -0.040 & 0.534 & 0.522 \\
\hline $6-10$ & 0.486 & 0.408 & -0.078 & 2.068 & 0.159 \\
\hline
\end{tabular}

** $p<0.01 ; * p<0.05$

Time (sec)

1233456789101112131415161718192021222324252627

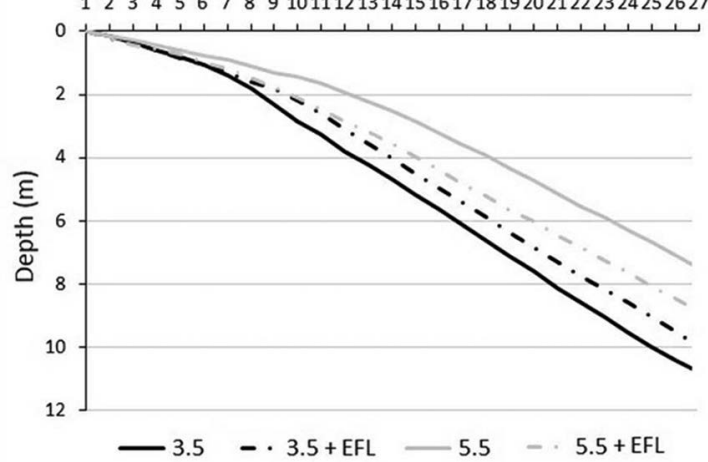

Figure 2. Mean sink profiles of baited hooks accordingly to leader length $(3.5 \mathrm{~m}$ or $5.5 \mathrm{~m})$ and presence or absence of electric fishing lights (EFL) during the first $27 \mathrm{sec}$ after deployment (corresponding to bird scaring line coverage).

of EFL, was deeper than the diving range of Thalassarche albatrosses within the $50 \mathrm{~m}$ astern critical zone.

The ICCAT recommendation 11-09 (http://www.iccat. int/en/Recs-Regs.asp) stipulates that in the area south of $25^{\circ} \mathrm{S}$, longline fleets of ICCAT members have to use at least two of three recommended mitigation measures (night

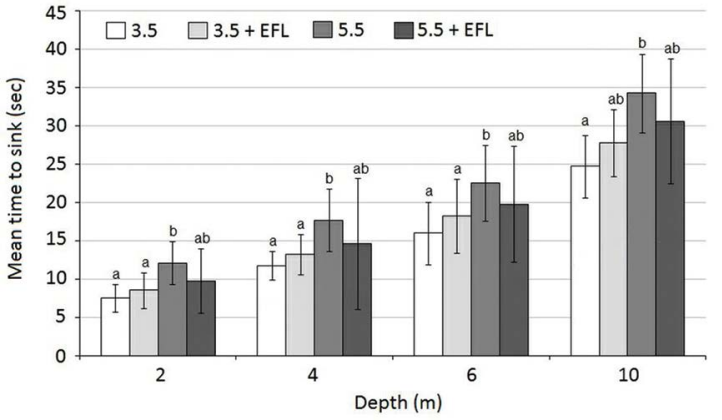

Figure 3. Mean time delayed by baited hooks under each treatment to $2 \mathrm{~m}, 4 \mathrm{~m}, 6 \mathrm{~m}$ and $10 \mathrm{~m}$ depths. The bars represent Standard Deviation. The mean time to sink at each depth class was compared between treatments using One-way ANOVA after square root transformation, followed by Tuckey test. Into each depth class, means values significantly different $(p<0.05)$ are not accompanied by common letters.

setting, line weighting and bird scaring lines). However, two (3\%) of the 66 monitored baited hooks were believed to have been retrieved by medium-sized diving petrels from $7 \mathrm{~m}$ and $10 \mathrm{~m}$ depths to near the surface, despite the darkness of the night (new moon) and the utilization of recommended line weighting. This fact reinforces the 


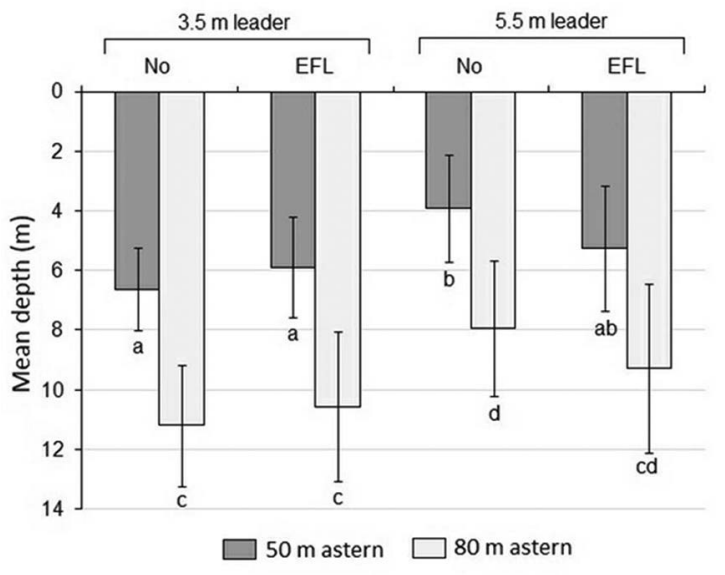

Figure 4. Mean depth of baited hooks under each treatment after 17 sec and $27 \mathrm{sec}$, corresponding to $50 \mathrm{~m}$ and $80 \mathrm{~m}$ astern respectively. The mean time to sink at each depth class was compared between treatments using One-way ANOVA, followed by Tuckey test. Means values significantly different $(p<0.05)$ are not accompanied by common letters.

idea that the use of only two mitigation measures is not sufficient to reduce seabird bycatch to negligible levels in the SW Atlantic, given the great abundance of mediumsized diving petrels in this area (JIMÉNEZ et al., 2011; 2014). The remarkable ability of these birds to access baited hooks and retrieve them to or near the surface of the water also results in bycatch of less able diving species, such as endangered albatrosses (JIMÉNEZ et al., 2011; 2014).

In conclusion, our results indicate that the addition of EFL did not improve substantially the sink rate of baited hooks, hence they do not support the hypothesis raised among fishermen that the utilization of EFL would help mitigate seabird mortality. EFLs should not therefore be interpreted as a measure for mitigating seabird bycatch, and should always be utilized in combination with one of the line-weighting regimes recommended by ACAP and ICCAT best practices guides.

\section{ACKNOWLEDGMENTS}

The authors would like to thank the Programa Petrobras Ambiental, the major sponsor of the Projeto Albatroz, as well as the Brazilian Ministry of Fisheries and Aquaculture and the Albatross Task Force Program sponsored by RSPB, BirdLife International and Save Brazil. The authors would also like to express their special thanks to all the skippers and crewmembers who voluntarily took part in this study and gave their valuable contribution. Further, the Museu Oceanográfico "Prof.
Eliézer de Carvalho Rios" - FURG, provided important logistic support for the operations of Projeto Albatross in the port of Rio Grande.

\section{REFERENCES}

ANDERSON, O. R. J.; SMALL, C. J.; CROXALL, J. P.; DUNN, E. K.; SULLIVAN, B. J.; YATES, O.; BLACK, A. Global seabird bycatch in longline fisheries. Endanger. Species Res., v. 14, n. 2, p. 91-106, 2011.

ANDERSON, S.; MCARDLE, B. H. Sink rate of baited hooks during deployment of a pelagic longline from a New Zealand fishing vessel. N. Z. J. Mar. Freshw. Res., v. 36, n. 1, p. 185195, 2002

ACAP. Summary advice for reducing impact of pelagic longlines on seabirds. Guayaquil: Reviewed at the Eighth Meeting of the Advisory Committee, 2014. Punta del Este, Uruguay. Available at: <http://acap.aq/en/resources/bycatchmitigation/mitigation-advice/200-acap-review-of-mitigationmeasures-and-summary-advice-for-reducing-the-impact-ofpelagic-longlines-on-seabirds/file $>$. Accessed on: 10 Jan. 2013.

BROTHERS, N. P. Albatross mortality and associated bait loss in the Japanese longline fishery in the Southern Ocean. Biol. Conserv., v. 55, p. 255-268, 1991.

FREEMAN, K. Light sticks pull in swordfish despite some problems. Natl. Fisherman, v. 70, n. 4, p. 54-57, 1989.

GIANUCA, D.; PEPPES, F.; CÉSAR, J.; MARQUES, C.; NEVES, T. The effect of leaded swivel position and light toriline on bird attack rates in Brazilian pelagic longline. Guayaquil: Fourth Meeting of the ACAP Seabird Bycatch Working Group, Doc 40 Rev 1. 2011. Available at: <http:// bmis.wcpfc.int/docs/references/Gianuca_etal_2011_ SBWG4 Doc 40 Rev1 Brazil_LeadSwivel tori pelagic LL.pdf $>$. Accessed on: 10 Jan. 2013.

JIMÉNEZ, S.; DOMINGO, A.; ABREU, M.; BRAZEIRO, A. Bycatch susceptibility in pelagic longline fisheries: are albatrosses affected by the diving behavior of medium-sized petrels? Aquat. Conserv. Mar. Freshw. Ecosys., v. 22, n. 4, p. 436-445, 2012.

JIMÉNEZ, S.; PHILLIPS, R.; BRAZEIRO, A.; DEFEO, O.; DOMINGO, A. Bycatch of great albatrosses in pelagic longline fisheries in the southwest Atlantic: Contributing factors and implications for management. Biol. Conserv., v. 171, p. 9-20, 2014.

HUIN, N. Diving Depths of White-Chinned Petrels. Condor, v. 96, n. 4, p. 1111-1113, 1994.

ICCAT. Supplemental recommendation by ICCAT on reducing incidental bycatch of seabirds in ICCAT longline fisheries. ICCAT Recommendation 11.09. Doc. No. PA4-813A. 2011. Available at: $<$ http://www.ccsbt.org/userfiles/file/other_rfmo_measures/iccat/ ICCAT 2011-09.pdf $>$. Accessed on: 12 Jan. $201 \overline{3}$.

LEWISON, R. L.; CROWDER, L. B. Estimating fishery bycatch and effects on a vulnerable seabird population. Ecol. Appl., v. 13, n. 3, p. 743-753, 2003.

MELVIN, E. F.; HEINECKEN, C.; GUY, T. J. Optimizing tori line designs for pelagic tuna longline fisheries: South Africa. Washington Sea Grant Report. Seattle: University of Washington. 2009a. Available at: <http://wsg.washington. edu/mas/pdfs/ToriLinesLR.pdf $>$. Accessed on: 10 Jan. 2013. 
MELVIN, E. F.; GUY, T. J; ROSE, B. Branchline weighting on two Japanese joint venture vessels participating in the 2009 South African tuna fishery: a preliminary report. Washington Sea Grant Report. Seattle: University of Washington. 2009b. Available at: <http://wsg.washington.edu/mas/pdfs/ WeightedBranchline_PrelimRep09.pdf $>$. Accessed on: 10 Jan. 2013.

ORTIZ, M.; SCOTT, G. P. Standardized catch rates for blue marlin (Makaira nigricans) and white marlin (Tetrapturus albidus) from the pelagic longline fishery in the northwest Atlantic and the Gulf of Mexico. Collect. Vol. Sci. Pap. ICCAT., v. 53, p. 231-248, 2001.

PETERSEN, S. L.; HONIG, M. B.; RYAN, P. G.; UNDERHILL, L. G.; GOREN, M. Gear configurations, line sink rates and seabird bycatch in pelagic longline fisheries. In: PETERSEN, S. L.; NEL, D. C.; RYAN, P. G.; UNDERHILL, L. G. (Eds.). Understanding and Mitigating Vulnerable Bycatch in southern African Trawl and Longline Fisheries. Cape Town: WWF South Africa Report Series - 2008/Marine/002, 2008. p. 166-177.
PRINCE, P. A., HUIN, N.; WEIMERSKIRCH, H. Diving depths of albatrosses. Antarctic Sci., v. 6, n. 3, p. 353-354, 1994.

ROBERTSON, G.; CANDY, S. G.; WIENECKE, B.; LAWTON, $\mathrm{K}$. Experimental determinations of factors affecting the sink rates of baited hooks to minimize seabird mortality in pelagic longline fisheries. Aquat. Conserv. Mar. Freshw. Ecosys., v. 20, n. 6, p. 632-643, 2010.

ROBERTSON, G.; CANDY, S.; G.; HALL, S. New branch line weighting regimes to reduce the risk of seabird mortality in pelagic longline fisheries without affecting fish catch. Aquat. Conserv. Mar. Freshw. Ecosys., v. 23, n. 6, p. 885-900, 2013.

ROLLISON, D. P.; DILLEY, B. J.; RYAN, P. G. Diving behavior of white-chinned petrels and its relevance for mitigating longline bycatch. Polar Biol., v. 37, n. 9, p. 1301-1308, 2014.

RONCONI, R. A.; RYAN, P. G.; ROBERT-COUDERT, Y. Diving of Great Shearwaters (Puffinus gravis) in cold and warm water regions of the South Atlantic Ocean. PLOS ONE, v. 5, n. 11, p. e15508, 2010. 